\title{
THERMAL PROPERTIES OF PLASTER REINFORCED WITH DATE PALM FIBERS
}

\author{
Mokhtar RACHEDI ${ }^{1,2^{*}}$, Abdelouahed KRIKER $^{1,2}$ \\ ${ }^{1}$ Departement of Civil Engineering, University Kasdi Merbah, Ouargla, Algeria. \\ ${ }^{2}$ Laboratory of Exploitation and Valorization of Natural Resources in Arid Zone, University Kasdi \\ Merbah, Ouargla, Algeria. \\ corresponding author: mokedi@hotmail.fr.
}

\begin{abstract}
This study aims both to investigate the thermal properties of plaster reinforced with date palm fibers and local natural resources valorization to batter using materials construction. For that, studying the effect of addition date palm fibers on the plaster's thermal properties is a significant point. In this work, we measured effective thermal conductivity, thermal diffusivity, specific heat, and thermal effusivity of date palm fibers reinforced plaster has been studied by CT meter. Samples configurations with four lengths $(10 \mathrm{~mm}-40 \mathrm{~mm})$ and four-weight ratios $(0.5 \%-2 \%)$ of palm fibers in plaster. The results obtained demonstrate that an increase in the fraction of date palm fiber engenders to a significant decrease in the thermal conductivity, thermal diffusivity, and effusivity, even an increase for the specific heat of different types of samples. Finally, this study is a contribution to the valorization of local materials in southern Algeria, and results encourage the use of plaster and date palm fibers in the field of construction and go to eco-friendly buildings.
\end{abstract}

\author{
Keywords: \\ Plaster; \\ Date palm fibers; \\ Thermal conductivity; \\ Specific heat; \\ Thermal diffusivity.
}

\section{Introduction}

Building materials reinforcement by natural fibers was very early used in history. Examples of this are mud blocks of brick reinforced by straw or horsehair incorporation into the coating mortars. In 1970, several studies existed to develop these materials using to replace fibers asbestos in prefabricated fibre-cement profiled elements (cladding, tiles, plates, etc.). Natural fibers using, and mainly plant fibers as a reinforcement of materials composite has two main advantages. First, fiber's availability at low cost and their use in construction provides new agricultural materials opportunities. Secondly, plant fibers recovery reduces environmental impacts compared to conventional composites since they are renewable, biodegradable, $\mathrm{CO}_{2}$ neutral raw materials, and requires little energy to be produced [1]. Algeria located in North Africa that has a large number of date palms and plaster deposits. This present work contribution to local resources development and its integration in rational use in the construction field. These new eco-composites have interesting thermal and mechanical properties. Several studies have investigated the determinate problem of physical and mechanical composite materials properties based on natural fibers and other materials (matrices) for decisionmaking regarding the characterization of natural fibers properties to integrate and use them in building applications. M. Khenfer et al [2], studied a plaster composite reinforced with Cellulose fibers; the obtained results have shown that there is an improvement in various mechanical properties. A. Kriker et al [3], also made significant findings results in his study on mechanical properties of date palm fibers and concrete reinforced with date palm fibers in hot-dry climate. I. Amara [4], examined the thermal conductivity of an insulating plate made by cement and palm fibers; the obtained results have shown that thermal conductivity was decreased by including the palm fibers. The same conclusions found I. Boulaoued et al [5] through his research on the determination of thermal conductivity and diffusivity of new building insulating materials. A. Djoudi et al [6] investigated another composite consist of the plaster, gravel, and palm fibers, it was mentioned that the addition of palm fibers improves considerably, the thermal conductivity, specific heat, and thermal diffusion. In another work, 
N. Fatma et al [7], proposes the use of doum palm fibers in the mortar of gypsum to improve density and thermal conductivity. Bederina et al. [8], studied the effect of adding wood shaving on the thermal properties of sand concrete experimentally. It was found that the addition of wood shaving reduces the density of the composite and affects thermal conductivity, which decreases with the increase of the ratio of wood shaving. This literature works with a global trend towards expanding the eco-materials using in construction by reinforcing building materials with plant fiber. We note that there are important results findings by most researchers in this field. In the present work, two main objectives were interesting. The first is thermo-physics properties measurement of plaster composites by adding local date palm fibers. Second, new products developed by local materials such as plaster and date palm fibers used directly in construction.

\section{Materials characterization}

\subsection{Plaster}

In all mixtures, the used plaster was produced by heating between $120^{\circ} \mathrm{C}$ and $160^{\circ} \mathrm{C}$ of oasis career in Ghardaïa city (southeastern region of Algeria). The chemical reaction can be formulated as follows:

$\mathrm{CaSO}_{4} \cdot 2 \mathrm{H}_{2} \mathrm{O} \rightarrow \mathrm{CaSO}_{4} 0.5 \mathrm{H}_{2} \mathrm{O}+1.5 \mathrm{H}_{2} \mathrm{O}$.

Table 1 represents the values of essential plaster properties [6].

Table 1: Essential properties of plaster.

\begin{tabular}{|c|c|c|}
\hline Apparent volumetric mass $\left[\mathrm{kg} / \mathrm{m}^{3}\right]$ & \multicolumn{2}{|c|}{$840-915$} \\
\hline Absolute volumetric mass $\left[\mathrm{kg} / \mathrm{m}^{3}\right]$ & \multicolumn{2}{|c|}{$1100-1300$} \\
\hline Refusal of sieve $800 \mu \mathrm{m}$ & \multicolumn{2}{|c|}{$2.60 \%$} \\
\hline Refusal of sieve $200 \mu \mathrm{m}$ & \multicolumn{2}{|c|}{$14.20 \%$} \\
\hline Finesse following the method of Blaine $\left[\mathrm{cm}^{2} / \mathrm{g}\right]$ & \multicolumn{2}{|c|}{$1500-8000$} \\
\hline \multirow{2}{*}{ Setting time $(E / P=0,6)$} & Beginning (min) & 7 \\
\hline & End ( $\min )$ & 15 \\
\hline \multirow{3}{*}{ Flexural strength $(E / P=0,6)[\mathrm{MPa}]$} & $1 \mathrm{~h}$ & 3.48 \\
\hline & $24 \mathrm{~h}$ & 3.73 \\
\hline & 7 days & 3.99 \\
\hline \multirow{3}{*}{ Compressive strength $(E / P=0,6)[\mathrm{MPa}]$} & $1 \mathrm{~h}$ & 8.51 \\
\hline & $24 \mathrm{~h}$ & 9.27 \\
\hline & 7 days & 10.11 \\
\hline
\end{tabular}

\subsection{Fibers}

In south Algeria, palm trees present prevalent species. Annually, in the harvest season, large quantities of fiber from these trees are eliminated. Therefore, to minimize the waste of this natural and renewable material, we opted for using the fibers to reinforce the plaster. In this study, we will use palm fibers from Oasis of Ouargla, the same fiber used by A. Kriker et al [3]. Table 2 shows the physical and mechanical properties of palm fibers.

Table 2: Physical and mechanical properties of the fibers.

\begin{tabular}{|c|c|c|c|}
\hline Apparent volumetric mass & \multicolumn{3}{|c|}{$\rho_{a}=512.21-1088.81 \mathrm{~kg} / \mathrm{m} 3$} \\
\hline Absolute volumetric mass & \multicolumn{3}{|c|}{$\rho_{s}=1300-1450 \mathrm{~kg} / \mathrm{m} 3$} \\
\hline \multirow{2}{*}{ Tensile strength [MPa] } & $L=100 \mathrm{~mm}$ & $L=60 \mathrm{~mm}$ & $L=20 \mathrm{~mm}$ \\
\hline & $170 \pm 40$ & $240 \pm 30$ & $290 \pm 20$ \\
\hline Failure of deformation & \multicolumn{3}{|c|}{$d=0.232$ (diameter of fibers $8 \mathrm{~mm}$ ) } \\
\hline Humidity rate & \multicolumn{3}{|c|}{$w=9.5-10.5 \%$} \\
\hline Rate of Absorption (after $24 \mathrm{H}$ ) & \multicolumn{3}{|c|}{$T A=96.83-202.64 \%$} \\
\hline Diameter (fibers used) & \multicolumn{3}{|c|}{$d=$ varied between $0.2-1 \mathrm{~mm}$} \\
\hline
\end{tabular}




\subsection{Lime}

An aerial lime with a $6 \%$ mass fraction was used as a retardant of plaster setting time. Its addition does not affect the mechanical properties, but it increases the time of employment of mixture by decreasing their solubility.

\subsection{Mixing water}

According to the standard NFB 12-401, the mixing water used is tap water of the laboratory of the University of Ghardaia.

\section{Preparation of samples}

\subsection{Pre-treatment and preparation of fibers}

It is essential, chemical treatment of natural fibers to eliminate the weak layers such as lignin and hemicellulose, which have no resistance to the alkali environment of the plaster. For this reason, it was taken the recommendations of Zbidi et al [9]. The palm fibers were immersed into a $1 \%$ concentration of $\mathrm{NaOH}$ solution at a temperature of $105{ }^{\circ} \mathrm{C}$ for $1 \mathrm{~h}$. Then well washed with water to remove dust and any excess of $\mathrm{NaOH}$ solution sticking to the surface of the fiber. After that, they were bleached with sodium chloride and finally washed again with water.

The palm fibers treated are manually cut to $10,20,30$, and $40 \mathrm{~mm}$ lengths.

\subsection{Composite preparation}

The fabrication of the various composites of the plaster and palm fibers; are prepared according to the standard NF EN 13279-1. We take the same compositions as M. Rachedi et al [10], in his study on the optimal composition of the plaster mortar; as follows:

- The report $\mathrm{W} / \mathrm{P}=0.6$.

- We add $6 \%$ of air lime as retarding of setting time.

- Respect the recommendations of kriker et al [3]; the need to immerse treated palm fibers in the water five minutes before being used in composites.

We designed by: W - water, P - plaster. To obtain a good homogeneity of the composites, we use two following procedure:

- Firstly, mixed in dry, the plaster and palm fibers.

- Secondly, water and aerial lime were added and mixed for $2 \mathrm{~mm}$.

\subsection{Samples}

The composites samples were produced using a manual mixing method and hand lay-up technique. The composites were produced by mixing the plaster, lime solution, and palm fibers, According to the above. The palm fibers were incorporated in plaster in the following weight fractions $0.5 \%, 1 \%, 1.5 \%$, and $2 \%$ for each length of $10,20,30$, and $40 \mathrm{~mm}$.

We have prepared three samples of each percentage of additives for the physicals and thermals characterization of the composites. Concerning the thermal characterization, samples were used steel mold with a dimension of $40 \times 80 \times 160 \mathrm{~mm}$, and slight consolidating by a metal rod. After $24 \mathrm{~h}$, specimens were demoulded and cured under laboratory conditions: $T=25 \pm 2{ }^{\circ} \mathrm{C}$ and relative humidity $R H=60 \pm 2 \%$ during 28 days.

\section{Methods of testing}

\subsection{Bulk density}

The bulk density of a specimen is the quotient of its dry mass divided by the exterior volume.

\subsection{The thermal characterization}

The thermal proprieties of the composites specimens were determined according to NFE99315, by the use of hot wire method (Fig. 1). The device used is the CT-meter developed by the Scientific and Technical Centre for Building (CSTB) of Grenoble. 


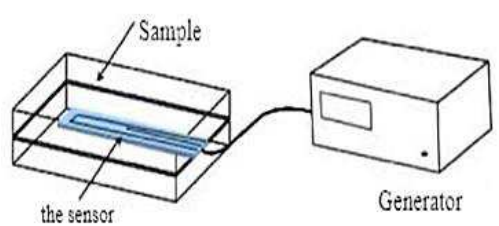

a)

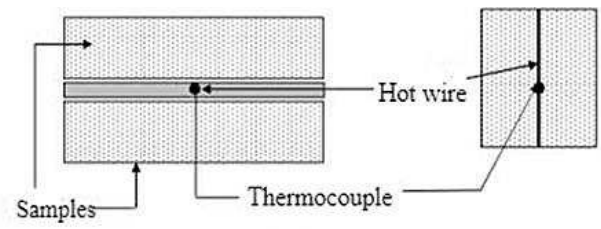

b)

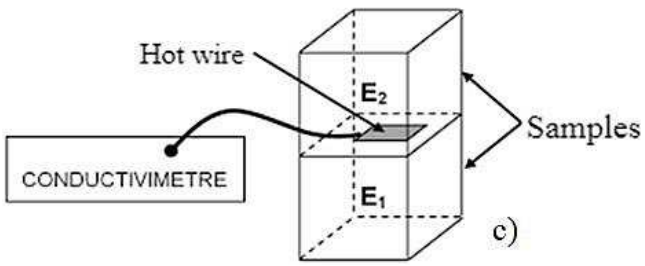

Fig. 1: a) The experimental device used for the measuring of thermo-physical properties; b) The longitudinal and transverse section on the samples during the test; $c$ ) Presentative schema of the experience.

The thermal conductivity and the specific heat were taken directly from the CT-meter, the thermal diffusivity a is calculated using the following equation (eq. (2)):

$\alpha=\frac{\lambda}{\rho c}$

where $\lambda$ is the thermal conductivity $(\mathrm{W} / \mathrm{mK}), \rho$ is the density $\left(\mathrm{kg} / \mathrm{m}^{3}\right), c$ is the specific heat $(\mathrm{J} / \mathrm{kgK})$.

\section{Results and discussion}

The thermal properties and density are such crucial physical property that needs to be evaluated for any new construction materials. Table 3 summarizes these properties (thermal conductivity, specific heat, and density) according to the percentage and the length of fibers, of the plaster reinforced with date palm fibers. The preliminary reading of the experiments' results shows that there is an improvement in the various thermal properties of the samples reinforced with fibers, compared with other samples non reinforced.

Table 3: Variation of bulk density, thermal conductivity, specific heat, and thermal diffusivity according to the percentage and length of date palm fibers.

\begin{tabular}{|c|c|c|c|c|c|}
\hline $\begin{array}{l}\text { Length of fibers } L \\
(\mathrm{~mm})\end{array}$ & $\begin{array}{c}\text { Percentage of fibers } \\
\text { (\% by mass) }\end{array}$ & $\begin{array}{c}\text { Bulk density } \\
\left(\mathrm{kg} / \mathrm{m}^{3}\right)\end{array}$ & \begin{tabular}{|c} 
Thermal conductivity \\
$(\mathrm{W} / \mathrm{mK})$
\end{tabular} & $\begin{array}{c}\text { Specific heat } \\
(\mathrm{J} / \mathrm{kgK})\end{array}$ & \begin{tabular}{|c}
$\begin{array}{c}\text { Thermal diffusivity } \\
\left(\mathrm{mm}^{2} / \mathrm{s}\right)\end{array}$ \\
\end{tabular} \\
\hline Reference plaster & $0 \%$ & 1240.13 & 0.671 & 1471.00 & 0.61 \\
\hline \multirow{4}{*}{10} & $0.5 \%$ & 1054.11 & 0.557 & 1735.780 & 0.52 \\
\hline & $1 \%$ & 1004.51 & 0.530 & 1750.490 & 0.50 \\
\hline & $1.5 \%$ & 979.70 & 0.517 & 1765.200 & 0.49 \\
\hline & $2 \%$ & 954.90 & 0.483 & 1809.330 & 0.47 \\
\hline \multirow{4}{*}{20} & $0.5 \%$ & 967.30 & 0.490 & 1838.750 & 0.47 \\
\hline & $1 \%$ & 917.70 & 0.476 & 1838.750 & 0.45 \\
\hline & $1.5 \%$ & 905.29 & 0.463 & 1868.170 & 0.43 \\
\hline & $2 \%$ & 892.89 & 0.456 & 1897.590 & 0.43 \\
\hline \multirow{4}{*}{30} & $0.5 \%$ & 954.90 & 0.470 & 1912.300 & 0.42 \\
\hline & $1 \%$ & 855.69 & 0.463 & 1927.010 & 0.42 \\
\hline & $1.5 \%$ & 830.89 & 0.450 & 1956.430 & 0.41 \\
\hline & $2 \%$ & 806.08 & 0.443 & 1971.140 & 0.41 \\
\hline \multirow{4}{*}{40} & $0.5 \%$ & 880.49 & 0.456 & 1956.430 & 0.40 \\
\hline & $1 \%$ & 818.49 & 0.423 & 2015.270 & 0.39 \\
\hline & $1.5 \%$ & 781.28 & 0.403 & 2059.400 & 0.37 \\
\hline & $2 \%$ & 756.48 & 0.396 & 2088.820 & 0.33 \\
\hline
\end{tabular}




\subsection{The bulk density}

Table 3 and Fig. 2, shows the variation of the density according to the percentage of fibers with different lengths. It is observed that the density decreases with increasing percentage and length of fibers. We found that the highest density corresponds to references composites without date palm fibers, while the lowest density was obtained in the composites reinforced with $2 \%$ and $40 \mathrm{~mm}$ length of fibers. In fact, this behavior can be explained by that the reduction in the density of the reinforced composites depends on the voids volume caused by adding the fibers. This results due to poor cohesion between the fibers and the mortars, which increases the porosity of the mortars leading to a decrease in their density. The reduction in density can be considered as one of the advantages of using natural fibers mixed with plaster because the final product is obtained very light. These are the same results as some researchers, such as Djoudi et al [6], N. Fatma et al [7], and A. Achour et al [11].

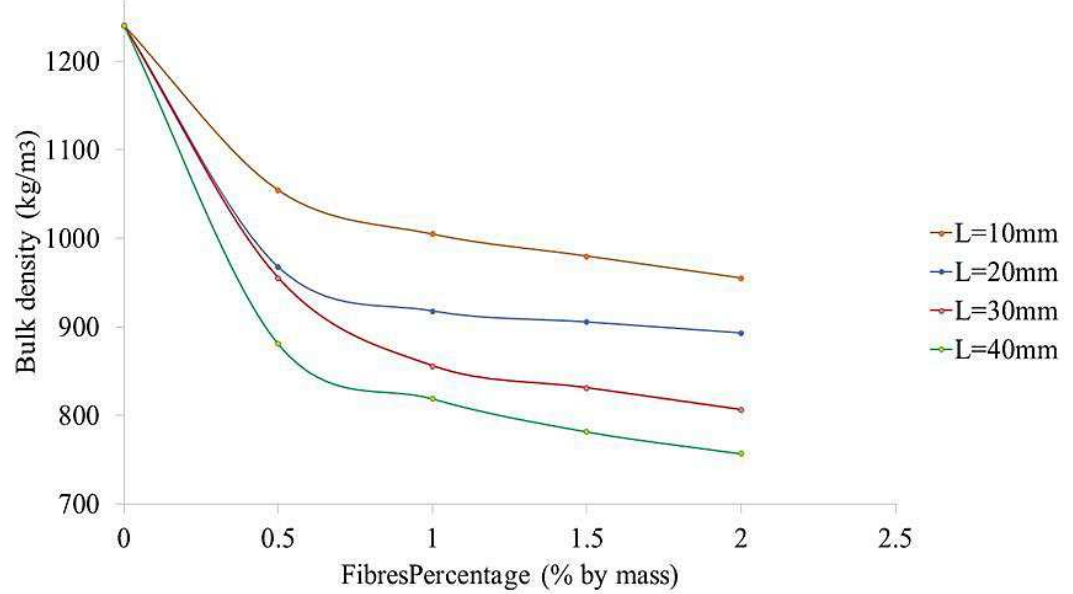

Fig. 2: The bulk density of the composites as a function of the percentage and length of date palm fibers.

\subsection{Thermal conductivity}

One of the most important characteristics of plaster is its significant heat insulation. In this study, we examine the relationship between the different quantities and lengths of date palm fibers used in the matrix and thermal conductivity of plaster reinforced with used fibers at the age of 28 days of hardening, is shown in the Fig. 3 and Table 3 . The results show that the composites with $2 \%$ by mass of date palm fibers of $40 \mathrm{~mm}$ length are the most insulating; Where its thermal conductivity decreased from $0.671 \mathrm{~W} / \mathrm{mK}$ for the composites without fibers to $0.396 \mathrm{~W} / \mathrm{mK}$ (with a $50 \%$ improvement); the less insulating is the composites with the lowest mass ratios in fibers $0.5 \%$ and the shorter in lengths $10 \mathrm{~mm}$.

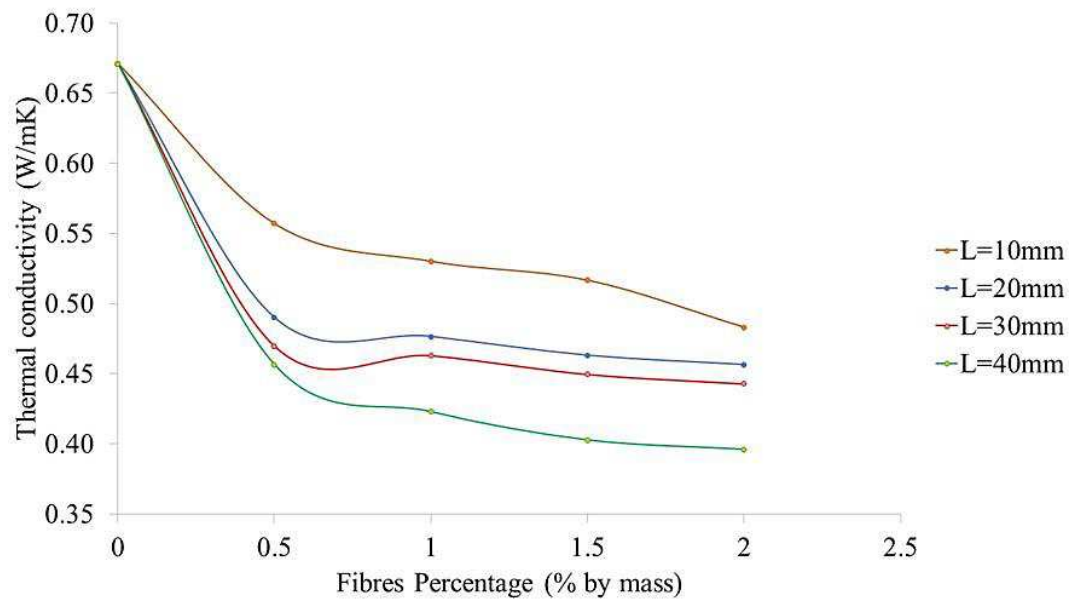

Fig. 3: The thermal conductivity of the composites as a function of the percentage and length of date palm fibers. 
We notice that the addition of fibers gradually and simultaneously reduces the thermal conductivity of the composites, and consequently increases its thermal insulation capacity. This behavior can give two explanations: The first is related to the insulating properties of palm fibers, which have a low thermal conductivity. The thermal conductivity of a composite depends on those of inclusions which constitute it. The lower the thermal conductivity of inclusions, the more the composite is insulating. The second is, the addition of natural fibers to reinforce the building materials leads to an increase in the proportion of voids in them, leading to a decrease in density of the composite and consequently, its thermal conductivity.

From the above, it can be concluded that the natural fibers content in the plaster plays a vital role in improving the thermal conductivity. The results are in agreement with the observations reported by several researchers like; B. Nagy et al [12], in his study on the effect of natural fibers on thermal properties of concrete, and V. Hospodarova et al [13], in his research on the influence of Cellulosic fibers on the physical properties of cement composites.

\subsection{Relationship between bulk density and thermal conductivity}

It was evident from previous results that, as the content palm fibers increases in the composite, the density decreases, making the composite lighter in weight, and also, the thermal conductivity improves a lot and makes the composite more insulating. This is a desirable characteristic of new engineering materials sort for and encourages broader use in the field. According to Fig. 4, it is shown that the thermal conductivity decreases with the decrease in density, and it is shown that there is a strong relationship between density and thermal conductivity when the correlation coefficient $R$ is approximately equal to 0.975 .

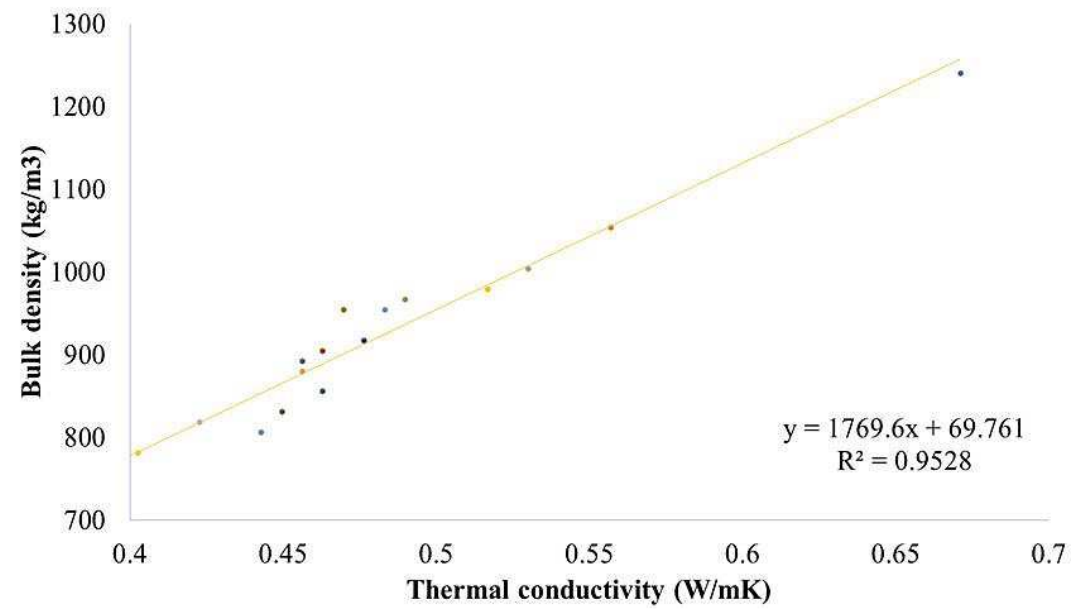

Fig. 4: Relationship between bulk density and thermal conductivity of the plaster reinforced with palm fibers.

It was exhibited that there was a substantial relationship between thermal conductivity and density. The results are in agreement with the observations reported in the literature $[6,8]$.

\subsection{Specific heat capacity}

Table 3 and Fig. 5, presents the evolution of specific heat capacity according to the percentage by weight and length of date palm fibers. It is observed that the specific heat capacity of the composites increases with the content in the mass and the length, of the palm fibers in the composite. This implies that increasing the palm fibers content gives the composite capacity to absorb more heat. This character makes the plaster reinforced with palm fibers more insulative than the pure plaster. The obtained results are following those in the literature. It is reported that, with increasing the natural fibers content, there is an increase in specific heat $[4,6]$. 


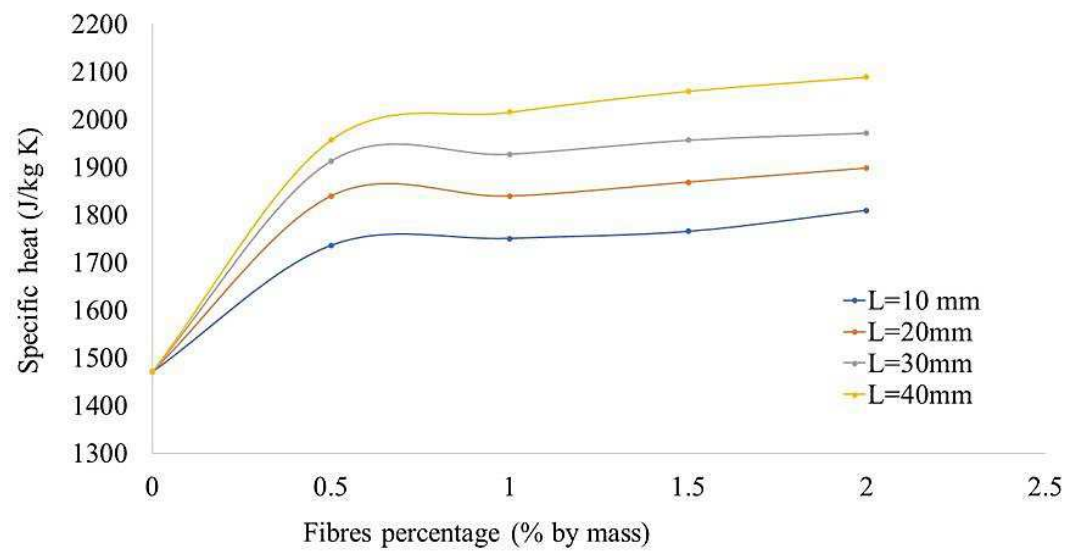

Fig. 5: The specific heat capacity of the composites as a function of the percentage and length of date palm fibers.

\subsection{Thermal diffusivity}

Thermal diffusivity is an important parameter to estimate the use of the material in the building, which is the rate of heat diffusion through these materials from a hot side to a cold side. Table 3 and Fig. 6 summarize the thermal diffusivity calculated according to Eq. (2). The results obtained indicate that the adding of the palm fibers to plaster permits to reduce the thermal diffusivity, so the transfer of heat flow takes more time to cross the composite in comparison with plaster pure. According to these results, we noted that the optimal fiber content is $2 \%$ and $40 \mathrm{~mm}$ of fiber length because this composition allows minimal thermal diffusivities. This affirms that the plaster reinforced with palm fibers as an excellent thermal insulator. These results can be explained by the alveolar structure of palm fibers, which do not allow heat to flow through them, and this is in accordance with the literature $[6,7]$.

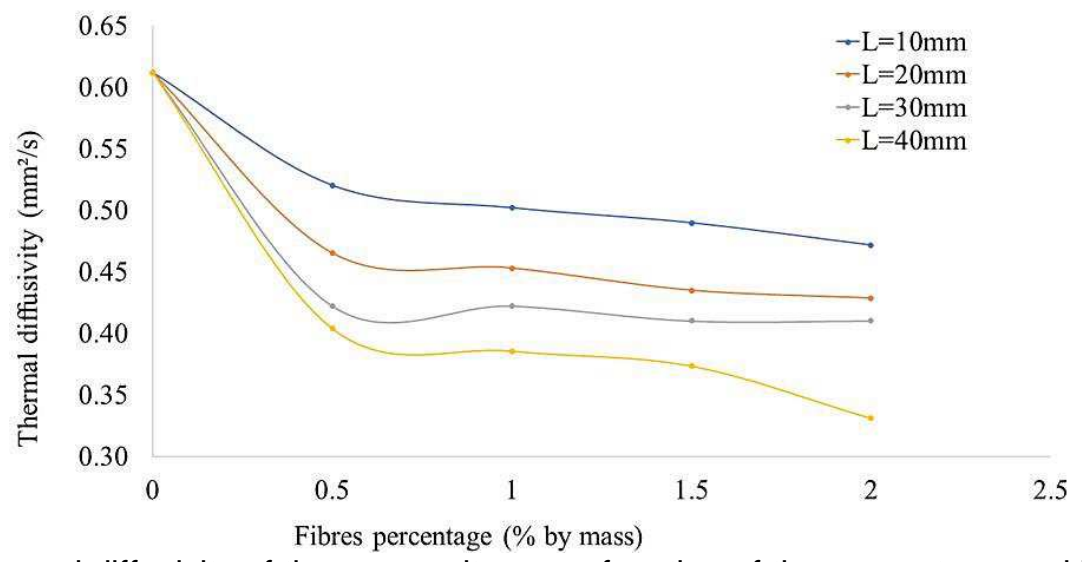

Fig. 6: The thermal diffusivity of the composites as a function of the percentage and length of date palm fibers.

\section{Recapitulation}

A quick view of the previous graphs, combining the results of thermal conductivity, density, and diffusivity, we can deduce that the more the fiber content in plaster composites are the better insulating becomes. We were found that the composites with a ratio of $2 \%$ in mass of fibers and a length of $40 \mathrm{~mm}$, give the best results in terms of thermal properties.

\section{Conclusions}

In this work, an experimental study on the possibility of date palm fibers utilization in the construction field. This kind of fibers gives us specific criteria, such as mechanical and thermal properties, when the results showed that rheological and the mechanical behavior of the material changed by incorporated vegetable fibers. Thus, palm fibers considerably increase material ductility in south Algeria, temperature value exceeds $48{ }^{\circ} \mathrm{C}$ in the summer, and less than $0{ }^{\circ} \mathrm{C}$ in the winter. 
Insulation materials are allowed to reduce heat loss and energy consumption. This study was designed to determine the thermal properties of a new local composite of plaster reinforced with various contents in lengths and mass of palm fibers. After results obtained in this work, the following conclusions can be cited:

- Palm fibers increase content reduces the weight of plaster composites by decreasing their density; Lighter weight obtained in composites with $2 \%$ by mass of date palm fibers of $40 \mathrm{~mm}$ length.

- The thermal conductivity decreased when the quantity of palm fibers content increased in the plaster composites, consequently increases their insulating capacity. The insulating specimen was observed with $2 \%$ by mass of date palm fibers of $40 \mathrm{~mm}$ length.

- The results have shown that a linear correlation of thermal conductivity with density $\left(R^{2}=\right.$ 0.952).

- Fiber content increasing in the plaster composites have an improvement in thermal diffusion and specific heat compared with pure plaster composites. The best results are shown in the samples containing $2 \%$ by mass of date palm fibers and $40 \mathrm{~mm}$ length.

- We found that it is necessary, after the excellent results obtained in the plaster's thermal properties reinforced with fibers, to expand the research to study the mechanical properties and the durability of the studied composite.

In conclusion, palm fibers using in the plaster composites give excellent thermal properties compared to synthetic insulation materials. We can note that the new materials were obtained competitive in terms of thermal properties and had the advantage of being an eco-materiel, harmless, and less expensive product.

\section{References}

[1] MAGNIONT, C.: Contribution to the formulation and characterization of eco-material of construction based on agromessources. Doctoral thesis, University of Toulouse III, 2011.

[2] KHENFER, M. M. - MORLIER, P. P.: Cellulose fibres reinforced plaster. Materials and Structures, 32, 1999 , pp. 52-58.

[3] KRIKER, A. - DEBICKI, G. - BALI, A. - KHENFER, M. M. - CHABANNET, M.: Mechanical properties of date palm fibres and reinforced date palm fibres concrete in hot-dry climate. Cement Concrete Comp, 27, 2005, pp. 554-564.

[4] AMARA, I. - BOULAOUED, I. - BAHLOUL, M. - MHIMID, A.: Determination of the thermal conductivity of an insulating plate made by cement and palm fibers. Modeling and experimentation, IJSET, 2016, pp. 94-101.

[5] BOULAOUED, I. - AMARA, I. - MHIMID, A.: Experimental Determination of Thermal Conductivity and Diffusivity of New Building Insulating Materials. Journal of heat and technology, 34(2), 2016, pp. 325-331.

[6] DJOUDI, A. - KHENFER, M. M. - BALI, A. - BOUZIANI, T.: Effect of the addition of date palm fibers on thermal properties of plaster concrete, experimental study and modeling. Adhesion Science and Technology, 28(20), 2014, pp. 2100-2111.

[7] FATMA, N. - LAMIS, A, - SALEM, M. - ZITOUNE, R. - ZIDI, M.: The effect of doum palm fibers on the mechanical and thermal properties of gypsum mortar. Journal of Composite Materials, 2019, pp. 1-19.

[8] BEDERINA, M. - MARMORET, L. - MEZREB, K. - KHENFER, M. M. - BALI, A. - QUE'NEUDEC, $M$.: Effect of the addition of wood shavings on thermal conductivity of sand concretes, experimental study and modelling. Construction and Building Materials, 21, 2007, pp. 662-668.

[9] SGHAIER, S. - ZBIDI, F. - ZIDI, M.: Characterization of doum palm fibers after chemical treatment abstract, 79, 2009, pp. 1108-1114.

[10] MOKHTAR, R. - KRIKER, A.: Optimal composition of plaster mortar reinforced with palm fibers. J Civil Eng Environ Sci., 4, 2018, pp. 44-49.

[11] ACHOUR, A. - GHOMARI, F. - BELAYACHI, N.: Properties of cementitious mortars reinforced with natural fibers. J of Adhesion Science and Technology, 10, 2017, pp. 1-25.

[12] BALÁZS, N, - SALEM, G. N. - DÓRA, S.: Thermal properties and modeling of fiber reinforced concretes. Energy Procedia, 78, 2015, pp. 2742-2747.

[13] HOSPODAROVA, V. - STEVULOVA, N. - VACLAVIK, V. - DVORSKY, T.: Influence of Cellulosic Fibres on the Physical Properties of Fibre Cement Composites. Materials Science and Engineering, 251, 2017, pp. 1-9. 